\title{
PRÁTICAS DE ARMAZENAMENTO DE SEMENTES DO POVO TICUNA NA TRÍPLICE FRONTEIRA AMAZÔNICA (BRASIL- COLÔMBIA-PERU)
}

\author{
BEATRIZ HELENA LOPEZ ARBOLEDA ${ }^{1}$ \\ Universidad del Valle (Colômbia)
}

FLÁVIO BEZERRA BARROS ${ }^{2}$

$U F P A$

\begin{abstract}
RESUMO: $O$ armazenamento de sementes empreendido pelos Ticuna faz parte de um complexo cíclico de relações envolvido nas paisagens, nas proximidades aos centros urbanos, nas formas de acesso, nos seus canais de troca e venda e nos seus propósitos. O presente artigo evidencia o armazenamento de sementes como uma das práticas ancestrais desenvolvidas pelo povo Ticuna na Tríplice Fronteira Amazônica (Brasil-Colômbia-Peru). Tal prática tem como intenção a utilização dessas sementes na próxima safra ou usá-las como estoques que podem servir de presente ou troca por outras sementes, por alimentos ou outro tipo de produto. De modo geral é desenvolvida pelas mulheres, pois são elas que conhecem as técnicas e os períodos apropriados. Embora o desenvolvimento dessa prática esteja diminuindo entre algumas etnias, no caso dessa etnia ainda se resgata sua importância como forma de resistência e luta, já que delas, as sementes, dependem boa parte dos povos, em grande medida por conta da soberania alimentar.
\end{abstract}

PALAVRAS-CHAVE: Ticuna; armazenamento; sementes; etnoconservação.

ABSTRACT: The seed storage system utilized by the Ticuna people is part of a cyclical complex of relationships connected to the landscapes, the vicinity to urban centers, the channels of trade and exchange, and its own purposes. This article discusses seed storage as a practice ancestrally developed by the Ticuna in the Amazon Triple Border (Brazil-Colombia-Peru). The practice's purpose is to preserve the seeds until the succeeding season, but also to use them as gifts or barter goods, exchanging them for other seed varieties, food, and other products. It is a practice mostly carried on by Ticuna women, who are familiar with the techniques and the time frames. Even though the practice has weakened amongst some indigenous peoples, the Ticuna still rely in its importance as a form of resistance, given that the seeds ensure food sovereignty.

KEYWORDS: Ticuna; storage; seeds; ethno-conservation.

\footnotetext{
1 Graduada em Administração do Ambiente pela Universidad Tecnológica de Pereira (Colômbia); Mestre em Agriculturas Familiares e Desenvolvimento Sustentável pela UFPA (Brasil). Doutoranda em Ciências Ambientais pela Universidad del Valle (Colômbia). E-mail: betyhelena@ hotmail.com .

${ }^{2}$ Doutor em Biologia da Conservação pela Universidade de Lisboa. Professor nos Programas de PósGraduação em Agriculturas Amazônicas e Antropologia da UFPA. Bolsista de Produtividade em Pesquisa do CNPq. E-mail: flaviobb@ufpa.br .
} 


\section{Introdução}

Atualmente a agrobiodiversidade está se vendo ameaçada pelos fenômenos da mudança climática, pela exploração excessiva dos recursos naturais, pelo uso inadequado da água e pelo manejo de espécies animais e vegetais com baixa variabilidade genética, o que influencia de grande forma na perda de materiais endêmicos ou autóctones, que possuem caraterísticas de resistência e rusticidade para enfrentar problemas de pragas, doenças e fenômenos climáticos externos (secas e enchentes) (RIVAS et. al., 2013).

Muitas variedades e espécies agrícolas já se extinguiram e outras correm risco de extinção, e a nossa alimentação se baseia em um número cada vez mais reduzido de espécies, com consequências para o meio ambiente e para a nossa saúde, que está diretamente associada à qualidade dos alimentos que comemos. Temos uma alimentação cada vez mais pobre, mas poucas pessoas se dão conta das interfaces entre os modelos agrícolas hegemônicos e o padrão alimentar que nos é imposto e das suas consequências socioambientais: marginalização socioeconômica dos agricultores tradicionais e familiares, perda da segurança alimentar, contaminação das águas, erosão dos solos, desertificação, devastação das florestas etc. Na agricultura, os impactos ambientais afetam a própria base de produção, o agroecossistema (SANTILLI, 2009).

No meio rural, em particular entre camponeses e povos indígenas, a adoção "massiva" das sementes híbridas e transgênicas e a aceitação ideológica e prática de uma dieta a partir de alimentos industrializados determinaram mudanças tanto na matriz tecnológica e na forma de organização da produção como na matriz de consumo alimentar familiar. Essas mudanças desorganizaram a base social e familiar da vida camponesa e dos povos indígenas, afetando elementos de sua identidade social e étnica. Isso contribui sobremaneira para a exclusão 
social dessas populações (CARVALHO, 2003).

Desta forma, as práticas vinculadas ao sistema agroalimentar na atualidade têm se visto vulneráveis, fenômeno intensificado pela distribuição geográfica do território e pelo acesso a novas formas da "civilização" devido à proximidade aos centros urbanos.

Embora as famílias ou as comunidades devessem produzir, selecionar e guardar as suas próprias sementes para o plantio na temporada seguinte, inclusive realizando trocas com outros grupos, num processo de partilhas que lhes permitissem aumentar a diversidade genética à sua disposição (CARVALHO, 2003), este processo intrínseco ao modo agrícola familiar precisa ser visibilizado e resgatado como mecanismo de resiliência ante novas práticas dispostas pela indústria agrícola e contínuas mudanças climáticas.

Nos últimos anos, tem-se dado atenção especial às comunidades agrícolas tradicionais não só como mantenedoras da diversidade biológica natural, em função das suas práticas agrícolas de baixo impacto, mas também como guardiãs da variabilidade e biodiversidade das plantas cultivadas e do conhecimento associado a toda essa riqueza (BECKER PELWING, BRANDAO FRANK e BERGMAN, 2008). De acordo com Bermejo Hernandez e León (1992), as variedades locais são aquelas que possuem a maior parte da variabilidade vegetal dentre as plantas cultivadas e, assim como tantos outros recursos naturais, o que se perde não se recupera mais.

O armazenamento de sementes é uma prática a qual se têm dedicado os agricultores e suas famílias durante milhões de anos. Tem Ihes permitido cultivar uma grande quantidade de distintas variedades locais, que têm conseguido adaptar-se às diferentes condições e mudanças do ambiente, tais como a escassez de água, os ventos fortes, os nutrientes limitados do solo, entre outros (FAO, 2014). Conseguir armazenar as sementes vivas em longos períodos assegura a preservação das espécies e das variedades de plantas valiosas (DORIA, 2010).

A prática de armazenamento de sementes, que realizam de forma tradicional as diversas etnias no mundo, é resultado do conhecimento adquirido de geração em geração: depois do ensaio-erro, tem-se como resultado práticas que permitem, no aspecto agrícola e cultural, garantir 
os elementos essenciais para as próximas safras. Em outras palavras, segundo Toledo e Barrera-Bassols (2009), além dos vínculos societários pelos quais existem os seres humanos, os seus vínculos com a natureza apresentam uma dependência tão universal quanto eterna.

Inseridos nesta perspectiva, para Pereira e Diegues (2010), os estudos da etnoconservação se direcionam para a classificação dos elementos naturais segundo os mitos, valores e visões de mundo das populações tradicionais. Ao cogitar este sistema de classificação por meio da abordagem cognoscitiva, procura-se a compreensão do modo como estes elementos culturais influenciam ou até mesmo determinam o manejo dos recursos naturais, ao mesmo tempo em que proporcionam a conservação dos mesmos. Esta hipótese está evidenciada nas práticas tradicionais ticuna, especificamente no caso do armazenamento de sementes. Seu significado ancestral e mitológico faz com que esta prática de manejo da agrobiodiversidade, que garante a quantidade e variedade dos seus alimentos, seja ainda mantida na atualidade. Porém, a proximidade aos centros urbanos faz com que a influência de práticas oriundas da globalização, como novas sementes nos mercados que "garantem uma boa safra", ofereça outra alternativa diferente de obter e tratar as sementes, gerando como consequência a erosão das práticas próprias da agricultura familiar e indígena.

Os estudos sobre as sementes são fortes nas perspectivas técnica e científica sobre detalhes de determinadas espécies de sementes e sobre formas de armazenamento, que avaliam as condições do ambiente a que podem ser submetidas, especificamente em laboratório. Já estudos mais próximos do aspecto social das sementes centram-se, no Brasil, na Região Sul, de forte campesinato, onde são identificadas diversas redes de troca e tipos tradicionais de armazenamento.

A semente, princípio da vida, constitui-se numa das mais importantes inovações surgidas durante a evolução das plantas. Carrega consigo o valor da sobrevivência, da resistência, da continuidade, da perpetuação. Explode em vida ou, protegida por seu envoltório, a gema permanece pacientemente latente até que o chão se torne úmido e a terra macia. Resultado de um longo processo natural de seleção, reluta em crescer até que as condições ambientais Ihe sejam favoráveis e, desta maneira, consegue sobreviver a períodos prolongados de 
estiagem ou a outras intempéries da natureza (ALMEIDA e FREIRE, 2003).

Mas as sementes também são o recipiente que transporta o passado, a visão, o conhecimento e as práticas acumuladas das comunidades em todo o mundo que, durante muitos anos, têm criado a base de tudo o que nos mantém no presente (LA VIA CAMPESINA, 2013).

Para os Ticuna, as sementes têm um significado mais além de uma estrutura botânica: os rituais, mitos, artesanato, tinturas, armazenamento, pesca, entre outros, fazem parte da cosmologia ticuna da semente. As formas de perceber as sementes que trazem os autores Mejia Gutierres (2003), Almeida e Freire (2003) e Via Campesina (2013) alimentam o conceito ticuna sobre a semente.

Em relação à temática de armazenamento de sementes pelos Ticuna, a seguir é exposta a metodologia da pesquisa sobre o armazenamento de sementes dos Ticuna, assim como uma necessária contextualização geral do povo Ticuna na Tríplice Fronteira Amazônica. A etnoconservação de sementes no universo Ticuna, o armazenamento e os sujeitos que desenvolvem este tipo de prática são os resultados abordados que levam a uma análise que pretende contribuir para a compreensão da etnoconservação ticuna.

\section{Os fazeres da pesquisa: falando de métodos}

Para identificar o armazenamento como uma das práticas de manejo e uso das sementes que desenvolvem os Ticuna das comunidades estudadas, consideramos os dados obtidos a partir da pesquisa Etnoconservação de sementes: trajetória, práticas e redes em comunidades indígenas Ticuna na tríplice fronteira amazônica (Colômbia, Brasil e Peru), onde, durante as primeiras aproximações com as comunidades e com seu entendimento e percepção sobre as sementes, identificamos as diversas práticas de manejo e usos das sementes.

Baseada em uma pesquisa de cunho etnográfico, a informação coletada resultou da convivência direta com as comunidades indígenas ticuna estudadas nos três países: Brasil, Colômbia e Peru. Para isso, 
desenvolvemos observação participante e contamos com a contribuição de membros da comunidade na elaboração de desenhos das sementes e suas formas de armazenamento, tabelas para identificar os tipos de sementes armazenadas e entrevistas semiestruturadas para conhecermos as práticas.

Segundo Malinowski (1986), a observação participante requer, além da convivência direita nas comunidades, determinado comportamento do pesquisador, já que influi no jeito como vai se desenvolver a pesquisa, do qual depende o aprendizado, a obtenção de dados e a análise posterior.

Uma vez que na presente pesquisa foi realizado o trabalho de campo e as técnicas inseridas como observação participante e entrevistas nos próprios sítios de moradia, tais procedimentos nos possibilitaram uma obtenção de dados reais e atuais sobre a situação de fronteira em relação às práticas de armazenamento de sementes. Assim, como cita Malinowski (1986) na sua reconhecida obra Os Argonautas do Pacífico Ocidental, relato de sua pesquisa com os indígenas dos arquipélagos da Nova Guiné Melanésia:

Como se tem dito, fundamental é se afastar da companhia dos outros brancos e permanecer com os indígenas num contato tão estreito como se possa, o qual só é realmente possível se se estabelecer moradia nos mesmos povoados indígenas (MALINOWSKI, 1986, p. 24).

Quase todo o trabalho de campo é um exercício de observação e de entrevista. Ambas as técnicas compartilham o suposto de tornar acessível a prática da totalidade dos fatos, e geralmente são complementares, para que se possa, assim, captar os produtos e os modelos, os comportamentos e os pensamentos, as ações e as normas, os fatos e as palavras, a realidade e o desejo. Observação e entrevista são dois modos básicos de obter informação e, sendo o trabalho de campo uma interação social, cada um deles mostra o aparente predomínio dos dois intervenientes na interação: o pesquisador, por um lado, e os sujeitos do estudo, por outro (VELASCO, 1997).

Em relação ao desenvolvimento da pesquisa, coletamos as informações em diferentes tempos. No caso da comunidade de Gamboa 
(Peru), na enchente e na seca dos sistemas hídricos, comportamentos que influenciam de forma direta o desenvolvimento da prática de armazenamento de sementes, já que esses tempos geram mudanças na paisagem, implicando em adaptação nas práticas de armazenamento de sementes na época da cheia e o seu semear nas épocas da seca, momento em que a paisagem permite o cultivo em zonas que na cheia ficam totalmente alagadas. Nas comunidades de Umariaçu II (Brasil) e San Sebastian de los Lagos (Colômbia), obtivemos informações indistintas no que diz respeito a épocas do ano, já que nestas localidades as estações do ano não influenciam a paisagem, pois elas se situam numa zona de terra firme, diferentemente de Gamboa, que está integrada a uma área de várzea, sendo mais suscetível às estações do ano na dinâmica de relação com o ambiente, sobretudo no que diz respeito aos sistemas de produção.

Os grupos que participaram na elaboração das tabelas variaram entre as três comunidades. Na comunidade de Gamboa, foram coletadas as informações a partir de três famílias. Na comunidade de Umariaçu II, o grupo correspondeu aos membros da Associação dos Artesãos e Cultura Indígena de Umariaçu (ACIU-EWARÉ) e da Organização das Comunidades Indígenas Ticunas do Umariaçu II e Alto Solimões (OCITU), sendo divididos em subgrupos que eles mesmos formaram. Finalmente, na comunidade de San Sebastian de los Lagos, foi abordado um grupo familiar e o grupo dos anciãos da comunidade. Nas práticas de armazenamento, percebemos as técnicas empregadas pelos moradores das três comunidades estudadas, além dos tipos de sementes, as quais são utilizadas na agricultura, na pesca e na confecção de artesanato.

\section{Os Ticuna na Tríplice Fronteira}

O território ticuna localiza-se na região do Rio Amazonas/Solimões, espaço onde confluem as fronteiras políticas de três países vizinhos: Brasil, Colômbia e Peru. Este fenômeno faz com que o atual território ticuna pertença a três estados nacionais diferentes; assim, os Ticuna, ao mesmo tempo em que reafirmam sua identidade étnica, também acolhem-se entre as diferentes identidades nacionais 
estabelecidas no marco dos três estados nacionais (LÓPEZ GARCES, 2002).

Geograficamente, e seguindo um eixo horizontal, o território ticuna estende-se desde a região de Chimbote, o ponto de povoamento ticuna mais ao ocidente, pertencente à Amazônia peruana, continuando pela Bacia do Rio Amazonas/Solimões até a região de Barreira da Missão, no município de Tefé, no Brasil, o qual constitui-se no extremo oriental do povoamento ticuna (OLIVEIRA, 1998).

Segundo o censo realizado pelo Instituto Brasileiro de Geografia e Estatística (IBGE) no ano de 2010, o total aproximado da população ticuna no Brasil era de 46.045 habitantes. Na Colômbia se apresenta uma população de 8 mil habitantes e no Peru um aproximado de 6.982 habitantes.

O território ticuna, além de ser uma ampla região dividida pelas fronteiras políticas entre Colômbia, Brasil e Peru, caracteriza-se por sua população multiétnica. Este povo mantém contatos com outros grupos indígenas, como os Yagua, Cocama, Huitoto, Cambeba e Culina, e com os "brancos" e "mestiços" que conformam a população rural e urbana nesta região de fronteiras (LÓPEZ GARCES, 2002). Porém, pela situação de fronteira, os povos indígenas sofreram, e ainda continuam a sofrer, o impacto da colonização, da construção de rodovias, dos grandes e pequenos extratores de recursos naturais e dos "culturizadores", que acham que para serem reconhecidos como cidadãos, os indígenas devem adaptar-se aos modelos da cultura ocidental. Sua localização é numa região de intensa exploração florestal, assim como de atividade de narcotráfico, sendo considerados em situação de vulnerabilidade média (MAYOR e BODMER, 2009).

A área de estudo, no primeiro plano, precisa de uma perspectiva abrangente pelo motivo de ser um território onde confluem três países, pela existência de um dos ecossistemas mais importantes no mundo, como é a Amazônia, pela existência da Bacia Alta do Rio Solimões, que nasce no Peru, passa pela Colômbia e continua no Brasil, o qual está composto por terras baixas e aluviares, o que sinaliza fertilidade para o uso agroflorestal e da biodiversidade, passando pela agricultura de várzea, pela hortifruticultura, pelo extrativismo animal e vegetal, pela agroindústria e pela bioindústria, bem como pelo artesanato utilizando 
produtos regionais e pelo turismo ecológico (MESORREGIÃO DO ALTO SOLIMÕES, 2008; CASTRO, 2009).

A identificação do armazenamento de sementes como uso e prática de manejo nas terras indígenas esteve focada em três comunidades indígenas ticuna nas fronteiras, as quais foram consideradas por sofrerem mais influência da situação de fronteira, dada a proximidade com os centros urbanos e todos os impactos socioeconômicos, culturais e ambientais a que estão sujeitas.

As comunidades indígenas ticuna que fizeram parte do estudo são: comunidade Umariaçu II, localizada aproximadamente a 4 quilômetros do centro urbano de Tabatinga/AM-Brasil, faz parte da Terra Indígena Umariaçu, que inclui as comunidades de Umariaçu I e II; o Resguardo Indígena Ticuna San Sebastian de los Lagos, localizado em território colombiano, no setor rural de expansão urbana ao noroeste da cidade de Leticia, na beira da Quebrada Yahuarcaca, afluente do Rio Amazonas, no $\mathrm{km} 5$ da estrada Los Lagos no município de Leticia, a qual atravessa o Resguardo na parte central e de forma perpendicular ao rio (REYES SANCHES, 2009); e a comunidade ticuna de Gamboa, povoado localizado no distrito de Yavari, região de Loreto, no lado peruano.

\section{A etnoconservação de sementes no universo ticuna}

A etnoconservação das sementes desenvolvida pelos Ticuna está baseada no uso, manejo e respeito à natureza, adquirindo assim um conhecimento dos comportamentos e manifestações do ambiente, propiciando a conservação de espécies. Na atualidade há uma luta contra a perda da terra e das práticas ancestrais, processos visivelmente influenciados pelos novos costumes adquiridos da "civilização" das cidades vizinhas.

O papel da etnoconservação na cultura desse povo contempla as práticas ticuna como formas de conservação da biodiversidade ligada fortemente às crenças, aos rituais e aos mitos, dinâmicas que se tornam indispensáveis para serem acionadas frente às problemáticas atuais. Estas dinâmicas são mantidas nas diversas relações do intercâmbio de conhecimento e dos produtos autóctones. Para citar exemplos, socializamos as narrativas dos anciãos da comunidade de San Sebastian 
de los Lagos:

Para procurar e ter sementes, hoje se tem que semear, o problema é que não se tem tempo para semear e, pior ainda, não temos terra, falta terra para a gente. Com as sementes se tem que fazer uma reflorestação como espécies de abai e "ojo de Dios", para isso temos que procurar um lugar perto do igarapé para reflorestar, aí teríamos problema com as pessoas que não têm respeito, elas vem para tirar o mato (Rafaela, avô do Resguardo Indígena San Sebastian de los Lagos, março de 2014).

Assim, as práticas sobre as sementes identificadas nas três comunidades têm a mesma base, mas apresentam algumas diferenças, dependendo do contexto. Na comunidade de Gamboa são referenciadas as sementes nas práticas agrícolas, em especial as que são manejadas no armazenamento artesanal para a safra seguinte. Na comunidade de San Sebastian de los Lagos, as fibras de palmeiras e sementes para o artesanato, artes de pesca e frutos do mato significativos. Na comunidade de Umariaçu II, as fibras de palmeiras e sementes e frutos utilizados para o artesanato e nas sementes das roças para o armazenamento. São referenciadas brevemente as espécies vegetais utilizadas nos rituais e as sementes mais empregadas nos processos de troca-venda e presentes.

O mercado tem seu cenário dentro das comunidades e nas cidades vizinhas, principalmente Tabatinga (Brasil) e Leticia (Colômbia), onde acontecem compra, venda e, escassamente, intercâmbio de sementes, já que este último acontece mais entre comunidades indígenas e com mais frequência nas comunidades com vínculos familiares. Outro tipo de canal das sementes são os tipos de fornecimento de sementes e fortalecimento no intercâmbio de saberes que apoiam os estados de cada país e ONGs, especificamente nos projetos de desenvolvimento rural ou de apoio e fortalecimento da segurança alimentar dos povos indígenas.

Apesar da proximidade com a área urbana, os Ticuna continuam tendo sua produção agrícola e artesanal regida pelos ciclos das águas, o que não os diferencia de outras comunidades localizadas na Amazônia. O tempo de enchente, cheia, vazante e seca determina o quê e onde 
será a produção. Essa decisão também é influenciada pelos hábitos alimentares que determinam os tipos de cultivo e criação de animais realizados por essa etnia. Porém, não são apenas esses fatores que influenciam a decisão, mas também as pressões externas, dos não indígenas, que modificaram e modificam seus hábitos alimentares, sociais, tecnológicos e de produção. "Para o índio, os resultados desse choque foram sumamente graves: houve mudança dos métodos de trabalho e dos hábitos alimentares [...]" (BATISTA, 2007 apud MACHADO et al, 2014).

O espaço relacionado aos locais de acesso foi catalogado pelos moradores das comunidades como quintais, mata, mata virgem, restinga (várzea) e roça. $\mathrm{O}$ acesso às espécies de hortaliças é mais comum, na comunidade de Gamboa, nas épocas de seca, quando podem desenvolver suas safras, já que, por morarem na várzea, a área ao redor das habitação alaga durante a época de cheia, dificultando seu cultivo. Na terra firme, no caso das comunidades de San Sebastian de los Lagos e Umariaçu II, é mais comum encontrar espécies herbáceas, arbustivas e árvores frutíferas com uso comestível, ritualístico, para pesca e artesanal.

\section{O armazenamento de sementes: prática tradicional entre os Ticuna}

Os Ticuna que moram em Gamboa, no Peru, têm se adaptado às condições dos seus locais de moradia. Sua história foi marcada por constantes deslocamentos até conseguirem, na atualidade, uma zona de várzea que permitiu à comunidade conviver com as condições do ambiente. Assim, as casas em formato de palafitas - para se preparar para as épocas da enchente e para os tempos da safra, em épocas de seca - é uma das formas de adaptação que permitem aos moradores desenvolver suas práticas tradicionais.

Uma das práticas tradicionais nesta comunidade é o armazenamento de sementes, desenvolvido na sua maioria pelas mulheres, utilizando técnicas nas épocas de enchente para depois utilizá-las na época da seca, cultivando-as. Este tipo de organização, com a figura feminina no desenvolvimento da agricultura, segundo 
Becker Pelwing, Brandao Frank e Bergman (2008), tem seus antecedentes nas civilizações primitivas, sendo considerado um aspecto com bastante ênfase na literatura.

Embora durante a pesquisa os homens ticuna tenham apresentado conhecimento das sementes e das formas de armazenamento, são as mulheres que fazem este tipo de prática, além de terem também a função de transmitir este conhecimento às netas e filhas.

A participação das mulheres nestas práticas agrícolas é muito comum e é de fato mais provável que tenham sido as mulheres que primeiro enterraram sementes no solo e iniciaram a doma dos animais jovens, alimentando-os e tomando conta deles, como faziam com seus filhos. As mulheres começaram a perceber a capacidade de germinação e, a partir deste fenômeno, a possibilidade de "concentrar" a produção dos alimentos. Além dessa questão, fatos históricos, embora fragmentados e não de todo compreendidos, levam a crer que a agricultura, uma vez estabelecida como modo de vida de civilizações antigas, era tida como objeto de importância fundamental e ligada, dessa forma, a todos os campos de relações da vida de certas comunidades, chegando a se fundir com acontecimentos religiosos e mágicos (BECKER PELWING, BRANDAO FRANK e BERGMAN, 2008).

Na pesquisa foram trabalhadas duas famílias de Gamboa, a família do avô Tertuliano e a família da Beatriz, as quais forneceram informações que permitiram conhecer as formas de armazenamento de sementes e como se encontra esta prática na atualidade. A família do avô Tertuliano fez desenhos dos tipos de sementes que são armazenadas, os tipos de armazenamento e a produção do fruto (Figura 1). Sementes de melancia (Citrullus lanatus), coentro (Coriandrum sativum), pepino (Cucumis Sativus), abóbora (Cucúrbita moschata), milho (Zea mays) e tomate (Solanum lycopersicum) são as mais armazenadas pela família.

Além do desenho, foram identificadas as espécies, o seu manejo e uso por parte dos moradores da comunidade de Gamboa (Quadro 1). Na elaboração da tabela, os membros da família comentaram sobre o principal uso das espécies citadas na alimentação diária. Do milho são reconhecidas três variedades: a nativa, para alimentos diários; a chicha, para fazer chicha, que é uma típica bebida fermentada de milho, muito 
utilizada nos labores de roça para combater a sede e dar energia durante o trabalho; e a variedade de pipoca, para fazer pipoca e para dar de comer às galinhas.

Figura 1 - Desenhos de sementes, formas de armazenamento e frutos da comunidade de Gamboa (Peru).

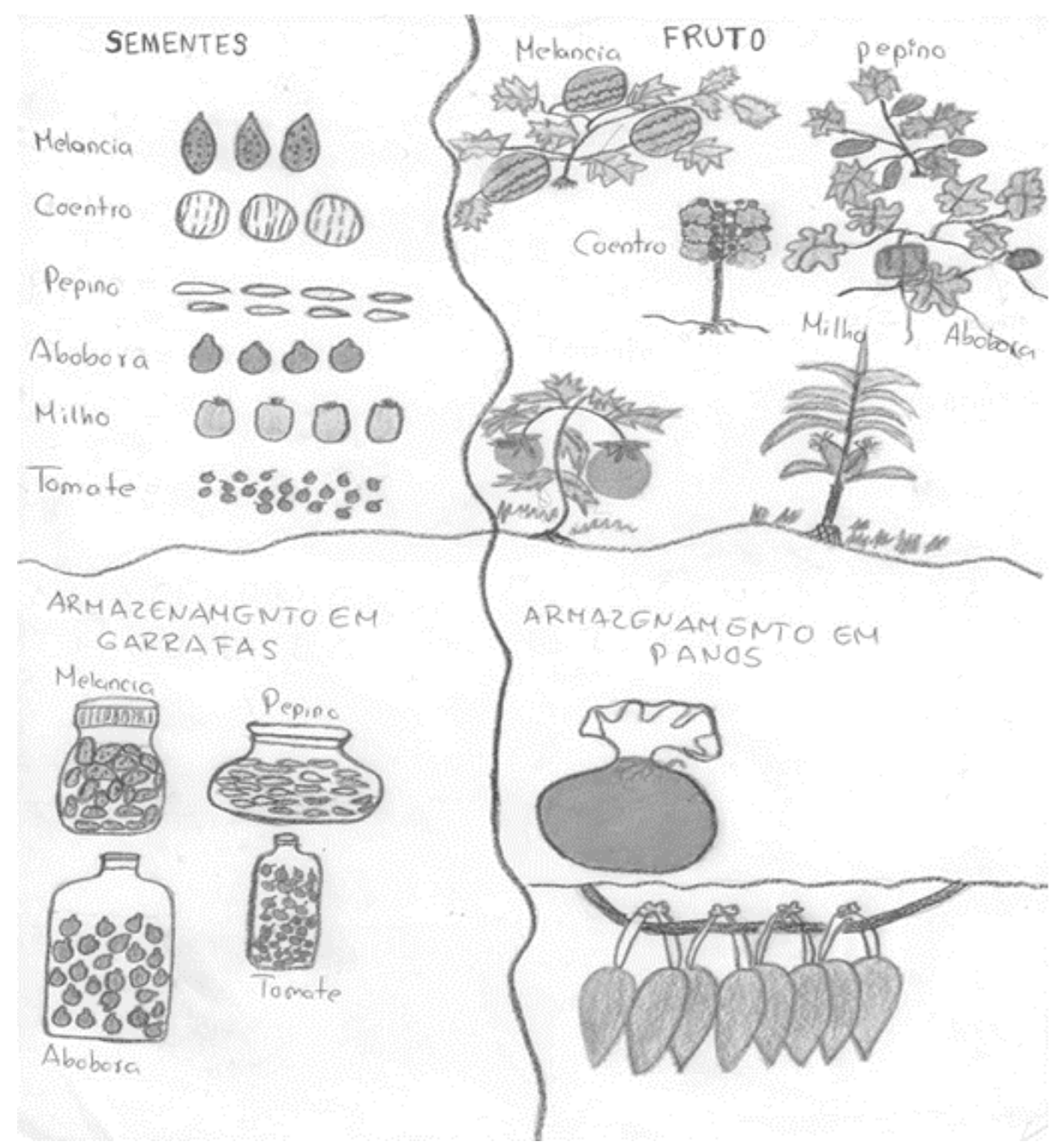

Fonte: Leila, filha do Tertuliano, Gamboa (Peru).

A macaxeira (Manihot esculenta), nas comunidades de Umariaçu II e San Sebastian de los Lagos, é uma das espécies principais na alimentação dos Ticuna. A macaxeira para alimentos e bebidas e a mandioca para fabricar farinha, que é consumida diariamente acompanhada de peixe. No tempo de enchente foram observadas grande quantidade de paus da mandioca, armazenados em palafitas para serem semeados para a época do verão, no mês de agosto.

$\mathrm{O}$ tomate não é muito consumido, a maioria é destinado para a 
venda no mercado de Tabatinga, assim como a melancia. Dentro das variedades são identificadas caraterísticas de gosto, sendo preferidas na sua alimentação as variedades nativas. Uma variedade de tomate (diferente) e uma variedade de melancia (paulista) foram identificadas como não nativas e, segundo os moradores, são umas das que mais precisam comprar no mercado. As sementes de milho são compradas em pouca quantidade e a macaxeira e mandioca não precisam de compra. Todas as espécies identificadas passam por processo de armazenagem tradicional em garrafas de vidro, sacolas de tecido e, no caso do milho, o sabugo, pois é onde os grãos ficam armazenados.

Os recipientes dos três tipos de armazenagem são dispostos nas áreas da cozinha, as garrafas no chão e as sacolas e sabugos pendurados perto do fogão de lenha. $\mathrm{O}$ armazenamento em garrafas é considerado como o recipiente mais atual nas comunidades, já que atende a embalagens que trazem da civilização e que depois da sua experimentação deu um bom resultado de armazenamento. São, de modo geral, utilizadas para as sementes de melancia, pepino, abóbora e tomate (Figura 1), que passam primeiramente por um processo de secagem ao sol por três dias no chão dos seus quintais.

O armazenamento no próprio sabugo do milho foi muito comum nas zonas da cozinha, perto do fogão de lenha. Estes não passam por processo de secagem ao sol. Os melhores sabugos da safra são escolhidos para seu armazenamento na cozinha, na sombra e perto do calor do fogão, até chegar a época de semear. Nas sacolas de tela que permitem a aeração das sementes, de modo geral, são utilizadas para as sementes de melancia e tomate.

Quadro 1 - Espécies, variedades, uso e manejo das sementes mais utilizadas na comunidade de Gamboa (Peru) - Família Tertuliano.

\begin{tabular}{|c|c|c|c|c|}
\hline Cultivo & Variedade & Origem & Uso & Práticas de Manejo \\
\hline \multirow{3}{*}{ Milho } & Nativa & Natural & $\begin{array}{c}\text { Comestível para sopas } \\
\text { e mingau }\end{array}$ & $\begin{array}{c}\text { É armazenada e quando não se } \\
\text { tem, se compra }\end{array}$ \\
\cline { 2 - 6 } & Chicha & Natural & Chicha (bebida típica) & $\begin{array}{c}\text { É armazenada e quando não se } \\
\text { tem, se compra }\end{array}$ \\
\cline { 2 - 6 } & Pipoca & Natural & Comida e animais & $\begin{array}{c}\text { É armazenada e quando não se } \\
\text { tem, se compra }\end{array}$ \\
\hline Macaxeira & Comestível & Natural & Comestível & Armazena-se o pão da mandioca \\
\hline
\end{tabular}




\begin{tabular}{|c|c|c|c|c|}
\hline Mandioca & Farinha & Natural & Fabricação de farinha & por 3 meses \\
\hline \multirow{2}{*}{ Tomate } & Região & Natural & \multirow{2}{*}{$\begin{array}{c}\text { Comestível e para a } \\
\text { venda }\end{array}$} & \multirow{2}{*}{$\begin{array}{c}\text { É armazenada e quando não se } \\
\text { tem, se compra }\end{array}$} \\
\hline & Interior & Diferente & & \\
\hline \multirow{3}{*}{ Melancia } & Redonda & Natural & \multirow{3}{*}{ Comestível } & \multirow{3}{*}{$\begin{array}{c}\text { É armazenada e quando não se } \\
\text { tem, se compra }\end{array}$} \\
\hline & Natural & Natural & & \\
\hline & Paulista & Diferente & & \\
\hline
\end{tabular}

Fonte: Pesquisa de campo (2014).

A família da Beatriz, do mesmo jeito que a família do avô Tertuliano, também forneceu informações sobre o armazenamento de sementes, apresentando os seus diferentes tipos de armazenamento em garrafa e em tela. Nesta família também foram identificadas sementes, suas variedades, usos e manejos (Quadro 2).

Em tela aparecem armazenamentos de semente de pepino e pimenta de cheiro e em garrafas de vidro, armazenamento de sementes de milho e abóbora. Além do armazenamento de sementes, a família tem uma plataforma (palafita) de plantas medicinais e armazenamento de manivas de mandioca e macaxeira, que são tanto para uso da própria família como para a venda.

Quadro 2 - Espécies, variedades, uso e manejo das sementes mais utilizadas na comunidade de Gamboa (Peru) - Família Beatriz.

\begin{tabular}{|c|c|c|c|c|}
\hline Cultivo & Variedade & Origem & Uso & Práticas de Manejo \\
\hline \multirow[t]{2}{*}{ Mandioca } & Amarela & \multirow{2}{*}{ Própria “chagra” (roça) } & Farinha & \multirow{2}{*}{$\begin{array}{l}5 \text { meses armazenada no quinta } \\
\text { (palafitas na época de cheia) }\end{array}$} \\
\hline & Branca & & Comestível & \\
\hline \multirow[t]{2}{*}{ Pepino } & Verde & \multirow{2}{*}{ Própria "chagra" (roça) } & \multirow{2}{*}{ Comestível } & Compra-se \\
\hline & Branco & & & Guarda-se em sacola \\
\hline \multirow[t]{3}{*}{ Milho } & Amarelo & \multirow[t]{3}{*}{ Própria "chagra" (roça) } & $\begin{array}{l}\text { Comestível, } \\
\text { chicha, } \\
\text { sancocho, } \\
\text { galinhas e para } \\
\text { venda }\end{array}$ & \multirow[t]{3}{*}{$\begin{array}{c}\text { Armazena-se em garrafa de } \\
\text { vidro }\end{array}$} \\
\hline & Pira & & \multirow{2}{*}{ Comestível } & \\
\hline & Suave & & & \\
\hline \multirow{2}{*}{ Tomate } & Interior (largo) & Compra-se & \multirow{2}{*}{ Comestível } & Armazena-se em garrafa \\
\hline & Amazonas & Armazena & & - \\
\hline Cebola & Cebollin & Própria "chagra" & Comestível & Em sacola e em muda \\
\hline
\end{tabular}




\begin{tabular}{|c|c|c|c|c|}
\hline \multirow[t]{2}{*}{ Coentro } & Cimarron & \multirow{2}{*}{ Própria "chagra" } & \multirow[t]{2}{*}{ Comestível } & $\begin{array}{l}\text { Próprio. Deixam cair sementes } \\
\text { na terra }\end{array}$ \\
\hline & De pais & & & Compram-se as sementes \\
\hline Melão & Melão & Própria "chagra" & Comestível & Armazena-se em garrafa \\
\hline \multirow{2}{*}{ Melancia } & Rayas & \multirow{2}{*}{ Própria "chagra" } & \multirow{2}{*}{ Comestível } & \multirow{2}{*}{ Compram-se as sementes } \\
\hline & Verde & & & \\
\hline \multirow{2}{*}{ Banana } & $\begin{array}{l}\text { Peruano } \\
\text { (grande) }\end{array}$ & \multirow[t]{2}{*}{ Própria "chagra" } & \multirow{2}{*}{ Comestível } & \multirow{2}{*}{ Com pica se cava o pau } \\
\hline & Beyaco (maior) & & & \\
\hline Alface & Comum & Compra-se & \multirow{2}{*}{ Comestível } & \multirow{2}{*}{ Compram-se as sementes } \\
\hline Couve & Comum & Compra-se & & \\
\hline
\end{tabular}

Fonte: Pesquisa de campo (2014).

As espécies diferentes das mencionadas pela família do avô Tertuliano são o pepino, a cebola, o coentro, o melão, a banana, a alface e a couve. A cebola e o coentro foram as mais observadas na época de enchente, ficavam na plataforma (tipo quintal); já as outras espécies, como pepino, melão, banana, alface e couve, foram mais percebidas na época da seca, já que elas são semeadas no quintal quando ele não fica alagado. Tal como na família do Tertuliano, todas as espécies são principalmente para o autoconsumo, sendo os excedentes vendidos ou dados de presente na mesma comunidade. Outra similitude encontrada é que a mandioca e macaxeira não são compradas e seu principal uso é para farinha (mandioca) e alimentos e bebidas (macaxeira).

Embora exista em quase todas as casas este tipo de prática, os moradores têm momentos em que precisam comprar sementes no mercado, já que as que armazenam não são suficientes para completar sua safra. Este tipo de problemática pode-se atribuir a que no momento em que decidiram comprar sementes no mercado, as sementes coletadas nas safras muitas vezes não deram fruto, sendo difícil obter suficiente quantidade de sementes a serem armazenadas.

$\mathrm{Na}$ comunidade indígena Umariaçu II, a qual faz parte da Terra Indígena Umariaçu, no Brasil, foi desenvolvida a pesquisa junto com as associações OCITU II e ACIU Eware, a primeira trabalha temáticas de pesca e a segunda trabalha os aspectos socioculturais da comunidade. Como participante da associação OCITU II, o Cristóvão forneceu 
informações sobre os tipos de sementes conhecidas na comunidade e seus diferentes usos, assim como diversos representantes da associação ACIU Eware, os quais permitiram participar de espaços de festividades para obter maiores informações. Na comunidade de Umariaçu II, os moradores comentam sobre o armazenamento de sementes, entre as mais comuns estão a melancia, o açaí, e o milho.

Processo da melancia: junta as sementes, seca elas por um dia e guarda em vasilhas durante dez meses. Igual se faz com o melão, pepino, jerimum e pimentão. Processo do açaí: apanha açaí, joga o caroço ao quintal, deixa secar, depois pega pouquinho, faz buraco e planta. Processo do milho: a semente seca no sol e guarda na saca (Jesuita e Zita, Umariaçu II, julho de 2014).

Além do conhecimento sobre os processos das sementes, Jesuita menciona como ela prepara seu lugar para cultivar:

Agora, para plantar, tem etapas no lugar onde serão semeadas as sementes. No primeiro momento se tem mato virgem, depois ela se tem que roçar e botar fogo, ficam capoeira, daí o mato cresce de novo, faz roça, e semeia (Jesuita, Umariaçu II, julho de 2014).

A anterior descrição do processo das sementes que faz Jesuita apresenta-se como refere Castro (2009) nas suas pesquisas em comunidades indígenas na Tríplice Fronteira Amazônica, onde o cuidado de coletar, selecionar e armazenar as sementes se constituem em processos que visam o futuro, em que as sementes utilizadas para produção, geralmente são procedentes dos ciclos produtivos anteriores.

Continuando com Castro (2009), os resultados da sua pesquisa referem que as sementes cultivadas são obtidas pelos próprios agricultores, por meio do armazenamento e/ou pelo compartilhamento entre e intra comunidades, representando $70,2 \%$. O mesmo ocorre com a reprodução vegetativa (manivas). São adquiridas no mercado local $19,1 \%$ de sementes, principalmente hortaliças. O escritório local do Instituto de Desenvolvimento Agropecuário e Florestal Sustentável do Estado do Amazonas (IDAM) fornece 10,6\% do total de sementes através do Programa de Distribuição de Sementes (milho, arroz, feijão e hortaliças). Existe uma relativa autonomia, superior a 70\% em relação ao 
mercado de sementes, seja ele representado indiretamente pelas doações do IDAM ou pela compra de sementes no mercado local. Ressalta-se, ainda, que as sementes compradas ou "doadas" são armazenadas pelos agricultores para uma posterior semeadura, ou seja, esses agricultores mantêm a posse das sementes.

$\mathrm{Na}$ comunidade de Umariaçu, outro tipo de pesquisa sobre sementes tem estudado a importância do milho dentro da produção ticuna. Machado et al (2014) mencionam que 13\% das roças são cultivadas com milho. Assim como a mandioca pode ser transformada em farinha, goma e tucupi, o milho pode ser transformado em uma série de outros produtos, como o fubá e a milharina, além de ser usado para alimentar os animais, especialmente galinhas e patos. Como nas economias de subsistência, os Ticuna utilizam quase toda sua produção para o consumo dos moradores da residência. Porém, eventualmente, parcela do excedente da produção é posta para ser comercializada na cidade e/ou mesmo na comunidade (MACHADO et al, 2014).

Assim como apresentam os resultados anteriores, em consonância com os resultados da presente pesquisa, pode-se supor que, nas comunidades indígenas da Tríplice Fronteira Amazônica, o armazenamento de sementes, embora seja permeado pelo mercado de sementes melhoradas e transgênicas no seu fornecimento ou na venda das mesmas, ainda é conservado como prática tradicional pelas famílias, e em especial as mulheres indígenas, o que garante tanto a conservação genética das espécies como a soberania alimentar, que de modo geral faz parte de um significado místico e religioso.

Em algumas das casas da comunidade de Umariaçu II foram observados armazenamento de sementes de uso alimentar e de tintura, em sacos de pano pendurados próximos ao fogão de lenha, guardando similitudes com os processos de armazenamento encontrados na comunidade de Gamboa. A identificação de sementes armazenadas para fins não alimentares, como foram as sementes utilizadas para tintura dos artesanatos, chama a atenção e tem relação com a importância da prática do artesanato e das formas de conservação utilizadas para manter este tipo de elemento para o desenvolvimento das suas práticas.

Em San Sebastian de los Lagos, durante entrevistas com as lideranças da comunidade, referenciaram que algumas famílias realizam 
armazenamento de sementes em garrafas, mas cada vez são menos as que realizam esta prática. Outro tema comentado foi o fornecimento de sementes por parte de instituições e do Estado, como registrado por uma interlocutora:

Muitas dessas sementes não são boas, não dá produtos para a coleta e aí meu marido acha que eu não plantei mais; eu plantei mesmo, mas não cresceu (Maria, Resguardo Indígena São Sebatian de los Lagos, maio de 2014).

Diante das experiências falidas, na atualidade se tem desenvolvido outros projetos de assistência técnica, em especial para hortas e plantas medicinais. No âmbito do resgate de práticas tradicionais, pode-se citar o Pragama Familias em Acción. Voltado para as comunidades indígenas de los kilómetros, o Programa, implementado pelo Ministério do Interior da Colômbia, possibilitou, no ano de 2014, a realização de eventos dedicados à troca de sementes entre as comunidades.

\section{Quem desenvolve as práticas}

Sem dúvida, a importância dos indígenas ticuna que desenvolvem as práticas em torno das sementes é inconteste, pois o conhecimento contribui de forma significativa para a conservação e preservação das mesmas. Após eles distinguirem as sementes, os seus usos e suas diversas caraterísticas, visitamos as suas moradias.

$\mathrm{Na}$ comunidade de San Sebastian de los Lagos, visitamos principalmente as casas dos anciãos, em companhia do morador Claudio, que deu apoio na tradução da língua. A comunidade se encontra em zona de terra firme, sendo uma pequena parte (zona das casas) zona de várzea que, na época, segundo os moradores, dava ótimo acesso a uma diversa quantidade de espécies vegetais, compatível com o número de habitantes, não gerando algum tipo de impacto significativo que pudesse alterar de forma negativa a paisagem da comunidade.

Desta forma, são identificadas quatro casas de anciãos e duas casas de adultos que são considerados e reconhecidos pela comunidade 
como os que mantêm ainda os costumes e práticas tradicionais. Dentre os adultos, a Ruth e o Claudio (da mesma família) são os moradores que têm desenvolvido trabalhos de liderança. Claudio, antigo cacique, lidera processos de desenvolvimento para sua comunidade e gestão de apoio público e privado em relação a temas de soberania alimentar, ampliação de território e luta pelos direitos humanos. Ruth se empenha na luta para conservar e para transmitir aos filhos as práticas artesanais e de agricultura e ele, Claudio, conservando a sua prática de pesca e agindo como monitor nos Lagos de Yahuarcaca.

Eles foram os intermediários para acessar os anciãos da comunidade, sendo identificadas algumas das casas dos anciãos Ilda, Rafaela, Victor e Hermelinda, Pascuala e Hernando (pais da Ruth). Ademais, foi identificado o acesso às espécies localizadas em zona vizinha que, embora não deu para perceber, segundo as falas dos moradores em geral da comunidade, é uma área com restrições de uso por ser zona privada e são já poucas as espécies que podem ser acessadas. Outra zona de acesso é a área de roça e mato que na atualidade encontra-se reduzida pelo incremento populacional da comunidade, apresentando, assim, pouca disponibilidade de espécies para seus diferentes usos.

As espécies do mato na comunidade de Gamboa são quase do mesmo tipo de acesso para as duas famílias, já que é uma pequena área e o deslocamento para a zona do mato fica atrás da escola e da casa comunitária, lá tem o acesso às espécies utilizadas para artesanato próprio e espécies frutíferas e animais para alimento. As zonas de roça, de modo geral, estão localizadas depois da zona do quintal, próximas à estrada do mato. O quintal das casas é a zona mais próxima, encontrando-se aí principalmente espécies de uso medicinal, algumas frutíferas e hortaliças.

Diferentemente do que ocorre na comunidade do Resguardo Indígena San Sebastián de los Lagos, o acesso às espécies em variedade e quantidade foi identificado na comunidade de Umariaçu II. Porém, a população vem aumentando, o que assinala para uma futura influência sobre as zonas onde são coletadas as espécies. Este elemento fica também evidente nas falas dos moradores das outras comunidades estudadas, cujo sonho é morar na comunidade de Umariaçu II, de onde 
são seus ancestrais.

Esta proposta atende ao comentado por Toledo e Alarcon (2012), em que afirmam que a forma de compreender os saberes locais de um grupo cultural é através da análise das relações entre as atividades práticas e o sistema de crenças. Foi assim que o sistema de crenças levou a presente pesquisa a inicialmente identificar quais as práticas dos Ticuna em torno das sementes, além de compreender os seus conhecimentos em relação a estes.

Um dos mais interessantes enigmas etnoecológicos são as formas como o pensamento do sujeito tradicional percebe, conceitua, classifica e utiliza seu espaço imediato, assim como sua correlação com as construções científicas, especialmente com as da ecologia da paisagem (TOLEDO e ALARCON, 2012).

\section{Algumas reflexões e considerações finais}

O manejo dos recursos, no caso das sementes, contribui para a agrobiodiversidade, a qual, graças às práticas de armazenamento, pode ser conservada nos ambientes naturais (in situ) e nas propriedades rurais pelos agricultores (on farm) (SANTILLI, 2009). Citando Altieri e Toledo Manzur (2011), as práticas tradicionais agrícolas, em relação às fortes mudanças climáticas, têm colocado de manifesto que a resistência aos desastres climáticos está estritamente relacionada com a biodiversidade presente nos sistemas produtivos.

Embora reconhecida a importância da agrobiodiversidade frente às problemáticas climáticas atuais, o conhecimento tradicional acumulado durante gerações através da experiência direta no manejo de recursos naturais tem sido esquecido e poucos esforços estão se realizando para proteger e conservar estes antigos sistemas de cultivo (ALTIERI e KOOHAFKAN, 2008).

O significado das práticas de armazenamento e de todas as práticas tradicionais dos Ticuna vai mais além das nossas compreensões e dos métodos quantificáveis, assim como cita Escobar:

Os conflitos sobre o acesso e o controle dos recursos adotam um caráter complexo desde o ponto de vista 
ecológico e político, se suprime a ideia amplamente reconhecida de que tudo pode ser reduzido a termos monetários (ESCOBAR, 2010, p.101).

Assim, seguindo Escobar (2010), o conflito gira em torno das formas de apropriação da natureza e, portanto, ficamos muito distantes do entendimento das representações coletivas nas formas distintas do fazer com/sobre a natureza. Em termos gerais, pode-se dizer que os modelos locais de cultura constituem montagem de significados e usos que, embora existam em contextos maiores de poder, não podem ser reduzidos a construções modernas, nem considerados à margem de alguma referência à cultura local e aos efeitos territoriais e de fronteira. Os modelos culturais e o conhecimento estão baseados em processos históricos, linguísticos e culturais que, embora nunca se encontrem isolados das histórias mais amplas, conservam uma certa especificidade do local. Além disso, muitos dos mecanismos e práticas em jogo nas construções da natureza, tais como fronteiras, classificações, representações, apreensões cognitivas e relações especiais, são específicas aos locais.

O anterior apoia a análise da presente pesquisa no sentido de se aproximar da compreensão de uma diversidade ecológica, agrícola e cultural conexa, embora com seus mundos próprios segundo seu território, o que dá riqueza às comunidades. Barros e Dias Varela (2004) colocam o manifesto às conexões dos conhecimentos tradicionais a partir de ampla troca e circulação de ideias e informações, e transmitidos oralmente, de uma geração a outra. Pela particularidade da Tríplice Fronteira Amazônica, estes processos de troca e circulação fazem parte das redes, temática abordada em outra parte da pesquisa Etnoconservação de sementes: trajetória, práticas e redes de circulação em comunidades indígenas Ticuna na tríplice fronteira amazônica (Brasil, Colômbia e Peru).

As práticas de armazenamento de sementes pelos Ticuna, além de se basear numa observação do seu entorno natural e do conhecimento do manejo e uso transmitido, segundo Altieri (1999), requer uma aprendizagem experimental. $O$ método experimental se faz patente na seleção de variedades de sementes para os ambientes específicos, mas também está implícito na prova de novos métodos de cultivo para se 
sobrepor a certas limitações biológicas ou socioeconômicas.

$O$ resultado destes métodos experimentais envolve mecanismos de adaptação. Um exemplo é citado por Santilli (2012), quando fala de sociedades que adaptam variedades de arroz ao cultivo aquático, submerso em água, em regiões úmidas, e há outras que adaptam variedades de arroz ao cultivo em regiões secas. As diferentes variedades de milho podem ser usadas para se comer diretamente na espiga, para alimentar os animais, para fazer pipoca, farinha ou para a fermentação da cerveja. São usadas também para fins ornamentais (principalmente aquelas com pigmentos coloridos), medicinais ou religiosos. A diversidade agrícola pode se expressar tanto em características perceptíveis pelo olhar humano, como variações de cor, forma, altura, tamanho e formato das folhas, quanto em variações genéticas, como resistência a secas, pestes e doenças, alto teor nutritivo etc., e a sua perda é difícil de ser avaliada com exatidão. A extinção dos saberes, das práticas e dos conhecimentos agrícolas é ainda mais difícil de ser mensurada.

É importante, dentro da análise anterior, o destaque do armazenamento de sementes pelos Ticuna, sendo que, segundo Rivas et al (2013), a prática tem como benefícios o acesso direto às sementes para suas safras, a obtenção de sementes sem ter que comprá-las, a manutenção das variedades e a conservação do conhecimento tradicional, que pode ser transmitido de geração em geração, compromisso e confiança, conservar o conteúdo genético dos ancestrais. Além disso, as práticas de armazenamento contribuem para a conservação da biodiversidade, das espécies nativas do local, da fauna benéfica que faz parte dos processos de polinização das espécies crioulas, diminui a tendência ao monocultivo e mantêm o equilíbrio ambiental (interação do homem com o seu entorno).

Cada espécie identificada na presente pesquisa tem seu uso e manejo associados à frequência da sua colheita, ao acesso a elas e à sua época de safra, embora nas três comunidades variem o tipo de espécie. Em Gamboa, por exemplo, há abundância de espécies vegetais, como legumes, mas tem escassez de frutos; o contrário do que acontece em San Sebastian de los Lagos. A existência de vínculos familiais permite o intercâmbio destes produtos, possibilitando, assim, complementar a 
diversidade nos seus hábitos alimentares.

A inclusão do uso de sementes melhoradas fornecidas pelo mercado é uma situação preocupante, já que, como fala Carvalho (2003), ao não mais utilizarem a semente "varietal" nativa (semente crioula), historicamente preservada pela prática da produção e de consumo do produto pelos camponeses e indígenas, abandona-se, também, a maneira tradicional camponesa e/ou indígena de produzir. A alteração na matriz de produção afeta a divisão do trabalho familiar e comunitário no mundo camponês, as práticas agrícolas e as de criação, a natureza dos insumos utilizados para a produção, a diversificação de cultivos e criações e as suas relações com o mercado, com a natureza e com a saúde das pessoas.

Nas práticas ticuna identificadas, as espécies utilizadas têm apresentado mudanças. A perda paulatina das atividades tradicionais e a escassez e o desaparecimento de espécies ocasionou uma queda no uso e manejo destas espécies, o que explica o fato de o conhecimento estar se tornando vulnerável em relação a estas espécies, sendo preciso o apoio ao resgate das práticas tradicionais e à transmissão oral do conhecimento tradicional.

O armazenamento de sementes é realizado nas três comunidades estudadas. O fato de estar sendo praticado com mais frequência em Gamboa demonstra que a agricultura, assim como a pesca, são as práticas tradicionais mais importantes para os moradores desta comunidade. O conhecimento em torno do armazenamento de sementes foi similar nas comunidades estudadas. A diminuição de armazenamento nas comunidades de Umariaçu II e San Sebastian de los Lagos está correlacionada à influência causada pela proximidade aos centros urbanos de Tabatinga (Brasil) e Leticia (Colômbia). Como os alimentos da comunidade de Gamboa dependem quase em sua totalidade da agricultura e da pesca, o armazenamento de sementes requer uma constante atenção e prática.

A identificação de algumas das pessoas que realizam práticas em torno das sementes foi necessária para ressaltar a importância destas para manter e resgatar os costumes, assim como para valorizar o conhecimento tradicional no uso e manejo destes recursos naturais, contribuindo como estratégia na etnoconservação das sementes do seu 
território. São elas: Juliana, Ermelinda, Magdalena, Rafaela, Lucia Fernandez, Ilda e Lucia Gomez do lado do Resguardo Indígena San Sebastian de los Lagos; Jesuita, Zita, Belisario, Jonato, Elvira, Ecilda, Arenaldi e Aldecir na comunidade Indígena Umariaçu II; e as famílias do Tertuliano, José e Beatriz no território peruano.

A função dos anciãos é muito importante, pois estes são as figuras com mais poder, indo além do papel de cacique, elas/eles são os que transmitem o conhecimento aos seus netos e os que tomam as decisões importantes nas comunidades, como a repartição de terra. Vejamos abaixo o que disse a senhora Ruth:

A educação é muito importante nos Ticuna. Não é dada pelos pais, mas, sim, pelas avós, por isso em ocasiões observam-se as avós com crianças e meninos e as pessoas não compreendem e dizem: que abusivas essas avós tão velhas com essas crianças (Ruth, San Sebastian de los Lagos, abril de 2014).

Os fenômenos naturais, construção de infraestrutura, tipos de produção não tradicionais e o aumento demográfico influenciaram na transformação do território, gerando, assim, conflito pela perda de terras, erosão dos recursos naturais e, portanto, das práticas tradicionais desenvolvidas nos espaços. Este tipo de transformação, segundo Gross et al. (1979) apud Trujillo (2008), afeta o acesso aos recursos necessários, obrigando-os a suprir as suas necessidades através da adoção de práticas de agricultura comercial e da incorporação ao mercado de trabalho (GROSS et al., 1979 apud TRUJILLO, 2008). Caso no qual vê-se prejudicada a prática de armazenamento de sementes, já que a aquisição de sementes comerciais nos mercados vizinhos deixa de lado paulatinamente a periodicidade da prática de armazenamento.

A autodenominação de agricultor foi relatada nas três comunidades. A maioria dos moradores das três comunidades se autodenomina agricultores, pescadores e artesãos. As suas práticas de uso e conservação das sementes estão relacionadas com as formas de autodenominação; assim, há sementes utilizadas para elaboração dos artesanatos e há sementes que são armazenadas para as próximas safras nas suas roças. 
Para as três comunidades indígenas estudadas, as sementes têm um significado especial que abrange seu conhecimento tradicional assim como sua aplicação por meio das suas práticas. Assim como fala Mooney (1987), as sementes utilizadas geralmente são procedentes dos ciclos produtivos anteriores. Porém, na atualidade, devido aos processos de colonização, à pressão sobre o território e à introdução de sistemas produtivos vindos da "Revolução Verde", os Ticuna têm perdido paulatinamente acesso e soberania em relação a seu entorno, gerando, assim, mudanças nas suas práticas tradicionais relacionadas às sementes.

Existe uma estreita relação de complementaridade entre as práticas tradicionais dos povos indígenas e a biodiversidade, que oferece os elementos necessários para a subsistência dos povos enquanto estes a salvaguardam por meio do conhecimento ancestral sobre o seu uso e manejo, que hoje vê-se interrompido pela apropriação estrangeira, tanto do território como de todos seus elementos, incluindo a vida dos povos e seus conhecimentos tradicionais. O uso da natureza ainda se mantém, mas foram apresentadas mudanças, como a exploração massiva de recursos, alterando, assim, o manejo e uso tradicional efetuado por muitas gerações. Esses processos constituem, portanto, uma das causas da atual erosão da diversidade genética, de espécies, de ecossistemas e de culturas.

O papel das comunidades tradicionais na conservação da biodiversidade na floresta tropical brasileira já foi analisado em comparação com as formas convencionais de utilização da terra em atividades agropecuárias. Neste caso, observou-se maior erosão genética, mesmo quando acompanhada de "medidas conservacionistas". Por outro lado, as formas de utilização dos recursos naturais pelas populações extrativistas e indígenas podem resultar em mínima erosão genética e maior conservação. Assim, o sistema desenvolvido pelas populações tradicionais tem demonstrado uso mais rentável da floresta em curto e médio prazo, mantendo a biodiversidade e os processos naturais de forma eficaz (DIEGUES e ARRUDA, 2000).

Com efeito, as práticas tradicionais em torno das sementes, como ainda fazem os Ticuna, em especial o armazenamento de sementes, 
permitem uma permanência no tempo da conservação de espécies não só de uso alimentar, mas também na conservação de espécies que fazem parte do desenvolvimento das diversas práticas tradicionais ticuna. Em face das influências da modernidade, gerando como resultado a adoção de novas práticas e a deterioração das práticas ancestrais ticuna, os órgãos estaduais dos três países e os centros de pesquisa devem promover e salvaguardar o acervo tradicional tanto destes povos indígenas como dos demais povos tradicionais que contribuem na etnoconservação na Tríplice Fronteira Amazônica.

\section{Referências bibliográficas}

ALMEIDA, Paula; FREIRE GALVAO, Adriana. Conservando as sementes da paixão: duas histórias de vida, duas sementes para a agricultura sustentável na Paraíba. In: CARVALHO, Horacio. Martins (Org). Sementes dos Povos. São Paulo: Editora Expressão Popular. 2003.

ALTIERI, Miguel Ángel. Agroecología: bases para una Agricultura Sustentable. Editorial Nordan-Comunidad. Septiembre de 1999.

ALTIERI, Miguel A.; TOLEDO MANZUR, Víctor Manuel. La Revolución Agroecológica en Latinoamérica. The Journal of Peasant Studies, v. 38, n. 3, p. 587$612,2011$.

ALTIERI, Miguel A.; KOOHAFKAN, Parviz. Enduring Farms: climate change, smallholders and traditional farming communities. Malaysia: Third World Network, 2008. (Environment and Development Series, 6).

BARROS, Ana Flávia; DIAS VARELA, Marcelo. Diversidade biológica e conhecimentos tradicionais. Belo Horizonte: ESMPU, Del Rey, 2004.

BECKER PELWING, Andréia; BRANDAO FRANK, Lúcia; BERGMAN, Ingrid. Sementes Crioulas: o estado da arte no Rio Grande do Sul. RER, Piracicaba, v. 46, n. 2, p. 391-420, 2008.

BERMEJO HERNANDEZ, Esteban; LEON, J. Cultivos Marginados: outra perspectiva de 1492. Jardín Botânico de Córdoba (España), Roma: FAO, 1992. p. 339. (Colección FAO: Producción y protección vegetal, 26).

CARVALHO, Horácio Martins. O oligopólio na produção de sementes e a tendência à padronização da dieta alimentar mundial. In: CARVALHO, Horácio Martins (Org). Sementes: patrimônio do povo a serviço da humanidade. São Paulo: Editora Expressão 
Popular, 2003.

CASTRO, Ivanilce. Governança Ambiental e Segurança Alimentar: a Agricultura Familiar no Alto Solimões, AM. 2009. 124 f. Dissertação (Mestrado em Ciências do Ambiente e Sustentabilidade na Amazônia) - Universidade Federal do Amazonas, Manaus, [2009].

CORTE CONSTITUCIONAL DE COLOMBIA. Sentencia C-921/07. Disponível em: http://www.corteconstitucional.gov.co/relatoria/2007/c-921-07.htm. Acesso em: 23 fev. 2015.

DANE. Compendio de normatividad de los resguardos indigenas en colombia en relacion con la informacion estadistica. Disponivel em: http://sige.dane.gov.co:81/gruposEtnicos/doc/NormatividadResguardosIndigenas.pdf. Acesso em: 23 fev 2015.

DIEGUES, Antonio Carlos; ARRUDA, Reinaldo Sérgio Vieira. Saberes tradicionais e biodiversidade no Brasil. Brasília/São Paulo: Ministério do Meio Ambiente/ Universidade de São Paulo, 2000.

DORIA, Jessica. Generalidades sobre las semillas: su Producción, Conservación y Almacenamiento. Cultivos Tropicales, v. 31, n. 1, p. 74-85, 2010.

ESCOBAR, Arturo. Una minga para el postdesarrollo: lugar, medio ambiente y movimientos sociales en las transformaciones globales. Programa Democracia y Transformación Global Universidad Nacional Mayor de San Marcos. Facultad de Ciencias Sociales. Fondo Editorial de la Facultad de Ciencias Sociales. Lima, febrero, 2010.

FUNAI. O Brasil Indígena. Disponível em: http://www.funai.gov.br/index.php/indiosno-brasil/o-brasil-indígena-ibge. Acesso em: 6 fev. 2015.

LA VIA CAMPESINA. Nuestras semillas, nuestro futuro. Cuadernos de la Vía Campesina, n. 6, jul. 2013.

LÓPEZ GARCES, Claudia L. Ticunas brasileros, colombianos y peruanos: etnicidad y nacionalidad en la región de fronteras del alto Amazonas/ Solimões. 2002. 373 f. Tese (Doutorado em Antropologia) - Universidade de Brasília - UnB. Brasília, Brasil, [2002].

MACHADO, Amanda et al. Economia Indígena: os modos de produzir e viver dos Ticuna na cidade de Tabatinga (AM). In: XIX ENCONTRO NACIONAL DE ESTUDOS POPULACIONAIS, 19, 2014, São Pedro-SP-Brasil. Resumos: ABEP, 24 a 28 de nov, 2014.

MAYOR, Pedro; BODMER, Richard. Pueblos Indígenas de la Amazonia Peruana. Iquitos, Perú: Centro de Estudios Teológicos de la Amazonía (CETA). 2009.

MALINOWKI, Bronislaw. Los argonautas del Pacífico Occidental. Barcelona: 
Editorial Planeta, 1986.

MEJIA GUTIERRES, Mario. Sementes Crioulas, um olhar a partir da Colômbia. In: CARVAlHO, M. (Org). Patrimônio de povo a serviço da humanidade. São Paulo: Expressão popular, 2003.

MESOREGIÃO DO ALTO SOLIMÕES. Consórcio Intermunicipal de Desenvolvimento Integrado e Sustentável da Mesorregião do Alto Solimoes. 2007. Disponível em: http//www.mesoaltosolimoes.com.br/index.php . Acessado em: 15 nov. 2016

MOONEY, Pat Roy. O escândalo das sementes: o domínio da produção de alimentos. São Paulo: Nobel, 1987.

OLIVEIRA, P. J. (Org.). Atlas das Terras Ticuna. Rio de Janeiro: Museu NacionaL/FINEP/PPG-7-CGTT, 1998.

FAO - ORGANIZACIÓN DE LAS NACIONES UNIDAS PARA LA ALIMENTACIÓN Y LA AGRICULTURA. Bancos de Semillas Comunitarios, Escuelas de campo y de vida para jóvenes agricultores. Roma: FAO, 2014.

PEREIRA, Barbara. DIEGUES, Antonio Carlos. Conhecimento de populações tradicionais como possibilidade de conservação da natureza: uma reflexão sobre a perspectiva da etnoconservação. Desenvolvimento e Meio Ambiente, Curitiba, n. 22, p 37 -50, jul-dez. 2010.

POVOS INDÍGENAS NO BRASIL (PIB). Quadro Geral dos Povos. Disponível em: http://pib.socioambiental.org/pt/c/quadro-geral. Acesso em: 1 fev. 2015.

REYES SANCHES, Giovanna Liset. Diálogo de saberes: plantas medicinales, salud y cosmovisiones. Bogotá: Editores e Impresores Ltda, 2009.

RIVAS PLATERO, Gonzalo Galileo et al. Bancos comunitarios de semillas criollas: una opción para la conservación de la agrobiodiversidad. Turrialba, Costa Rica: CATIE, 2013.

SANTILLI, Juliana. Agrobiodiversidade e o Direito. Outubro 1 de 2009. Correio Braziliense. Disponível em: http://www.ecodebate.com.br/2009/10/01/agrobiodiversidade-e-o-direito-artigo-dejuliana-santilli/. Acesso em: 1 mar. 2016.

A Lei de sementes brasileiras e os seus impactos sobre a agrobiodiversidade e os sistemas agrícolas locais e tradicionais. Bol. Mus. Para. Emílio Goeldi. Cienc. Hum., Belém, v. 7, n. 2, p. 457-475, maio-ago. 2012.

TOLEDO, Victor Manuel; BARRERA- BASSOLSB, N. La memoria Biocultural. La importancia ecológica de las sabidurías tradicionales. Barcelona: Icara Editorial, 2009. 
TOLEDO, Victor Manuel; ALARCON CHAIRES, Pablo Eulogio. La etnoecologia hoy: panorama, avances, desafíos. Etnoecologia, v. 9, n.1, p. 1-16, 2012.

TRUJILLO Osorio, Catalina. História y Economia: exploración cuantitativa de los ingresos en hogares indígenas. In: UNIVERSIDAD NACIONALDE COLOMBIA Sede Amazonia. Instituto Amazonico de Investigaciones IMANI. Gente Tierra y Agua en la Amazonia. Bogota, D.C, Colombia: Editora Guadalupe Ltda, 2008. v. 2.

VELASCO, Honorio. La lógica de la investigación etnográfica. Valladolid: Editorial Trotta. 1997.

Recebido em: 07/04/2016 * Aprovado em: 22/09/2016 * Publicado em: 31/12/2016 